\title{
Poniendo los cuerpos en la lucha contra la violencia basada en el género: el Tsunami Feminista en Chile el 2018
}

\author{
Putting bodies on the line in the fight against gender-based \\ violence: the feminist tsunami in Chile in 2018 \\ María José Contreras \\ Pontificia Universidad Católica de Chile \\ Escuela de Teatro \\ mcontrel@uc.cl
}

\section{Resumen}

Chile. Mayo 2018. Miles de mujeres salen a las calles para reclamar sus derechos, instalando en la agenda pública la crítica a la educación sexista, a la naturalización del abuso y el acoso sexual, y a la heteronormatividad. Las protagonistas de este movimiento social lo llaman un tsunami feminista. En este artículo me ocuparé del mayo feminista chileno desde la perspectiva de sus prácticas, puestas en cuerpo y performances. Me interesa pensar los palimpsestos que se configuran en los cuerpos de las protagonistas que reciclan y reversionan gestos, prácticas y acciones de las feministas chilenas que las precedieron.

Palabras clave: feminismos, activismos, performance, Chile.

\begin{abstract}
Chile. May 2018. Thousands of women occupy the streets to reclaim their rights, placing the criticism of sexist education, the naturalization of sexual abuse and harassment, and heteronormativity on the public agenda. The protagonists of this social movement call it a feminist tsunami. In this paper, I will discuss Chile's feminist May from the perspective of practices, embodiments, and performances. I am interested in the palimpsests configured in the protagonists' bodies while they recycle and re-perform gestures, practices, and actions used by the feminists who preceded them.
\end{abstract}

Keywords: feminism, activism, performance, Chile 


\section{De la violencia a la performance}

El movimiento feminista en Chile durante el 2018 surgió, en un primer momento, como crítica a la violencia sexual en los contextos universitarios. Los numerosos casos de acoso y abuso sexual sumados a la escasa reacción de las autoridades universitarias dejaron en evidencia la falta de una cultura institucional respecto a la violencia sexual, que se traducía en la invisibilización de los casos y el consiguiente abandono de las víctimas. Pero el movimiento feminista no se detuvo en denunciar la violencia sexual, avanzó hacia una crítica a la violencia estructural fundada en la heteronormatividad, es decir, en el régimen social, político y económico que define la heterosexualidad como la única forma "normal" de expresión de los afectos y deseos sexuales. El patriarcado establece una estructura jerárquica de género que ordena el mundo a partir de una distribución desigual de privilegios y oportunidades. La normatividad sexo-género y su rampante inequidad opera biopolíticamente disciplinando los cuerpos, normalizando la violencia y construyendo un imaginario fijo y restrictivo sobre lo que significa ser y lo que pueden hacer los "hombres" y las "mujeres".

El movimiento feminista que despertó en mayo del 2018 supo comprender que el patriarcado heteronormativo se basa en el control de los cuerpos. Es por esto que las tácticas feministas puestas en acción apelaron principalmente a la dimensión performativa de las corporalidades. La trinchera de lucha y resistencia no fueron los discursos grandilocuentes, sino que fueron los cuerpos, las cuerpas como dirían algunas feministas, que, desplegadas en las facultades y las calles, desafiaron el ordenamiento simbólico patriarcal. El auto denominado tsunami feminista corporalizó su crítica, encarnó sus principios y "performeó” su poderío.

En este artículo me ocuparé del mayo feminista chileno desde la perspectiva de sus prácticas, puestas en cuerpo y escenificaciones. Estoy segura que es en esta dimensión corporal y performativa, que yace gran parte de la eficacia política del movimiento. Me interesa pensar los palimpsestos que se configuran en los cuerpos de las actuales protagonistas que reciclan y reversionan gestos, prácticas y acciones de las feministas chilenas que las precedieron. Espero que este ejercicio me permita imaginar también, cómo estas tácticas corporales se proyectan hacia un futuro esplendor.

\section{Fuimos ola y nos convertimos en tsunami}

El 17 de abril de 2018 estudiantes de la Universidad Austral deciden tomarse el campus de la Facultad de Humanidades como protesta ante el letargo institucional para dar respuesta y seguridad a las víctimas de acoso y abuso sexual. Las 
estudiantes de la Universidad Austral se movilizan para denunciar la insuficiencia de los protocolos y la falta de reactividad de las autoridades antes los casos, siempre más frecuentes, de vulneración de las estudiantes y funcionarias. Esta movilización feminista encontró un sentido eco en otros establecimientos educacionales del país.

Diez días después del inicio de la toma en la Universidad Austral, se inicia la toma de la Facultad de Derecho de la Universidad de Chile como reacción ante el fallo del sumario al profesor Carlos Carmona, ex presidente del Tribunal Constitucional, quien fuera denunciado por acoso sexual por su entonces ayudante Sofía Brito. Después de ocho meses de proceso, y un sumario de más de cuatrocientas páginas, el 27 de abril Carmona es sancionado con tres meses de suspensión por "vulneración a la probidad administrativa". El fallo desató la furia de las estudiantes que convocaron una asamblea de emergencia a la que acudieron más de 600 personas. Reunidas en el patio de la Facultad de Derecho de la Universidad de Chile las estudiantes deciden tomarse el campus como señal de protesta. Como es consuetudinario en nuestro país en las tomas de establecimientos educacionales, las estudiantes dispusieron sillas en la reja, apuntando sus patas como púas de puercoespín hacia la calle. Colgaron además una guirnalda de sostenes y pusieron un gran lienzo que consignaba: Toma Feminista. Otro cartel se apropiaba de la consigna de las protestas acaecidas en España ante el escandaloso caso de La Manada y declaraba: \#HermanaYoTeCreo.

Las movilizaciones se propagaron con velocidad, en pocos días, los paros y las tomas alcanzaron diversas facultades, universidades y escuelas a lo largo de Chile. El 29 de mayo la Confech cuenta 32 facultades y 8 liceos movilizados. Cada facultad definió sus propias prioridades, las que fueron articulando en petitorios. Algunas reivindicaban la urgente necesidad de crear unidades de género en las universidades donde las estudiantes pudieran buscar asistencia legal y apoyo psicológico. Otras, exigían la expulsión de depredadores sexuales y la creación o corrección de los protocolos sobre violencia sexual. En algunos, se incluían demandas de carácter local como la instalación de mudadores en los baños de hombres y mujeres de los planteles.

El reconocimiento mutuo y la rabia sirvieron para sostener un movimiento que poco a poco fue adscribiendo a un deseo más ambicioso de cambiar el sistema heteropatriarcal para dar cabida a la diversidad, para minar los privilegios de género, raza y clase, para poco a poco avanzar hacia una sociedad más justa. Es así como a medida que el movimiento crece, el foco inicial se expande y surge la demanda por una educación no sexista. Las estudiantes exigen el uso de lenguaje 
inclusivo, la incorporación de autoras mujeres en las bibliografías de los programas de curso y paridad en el número de mujeres en puestos de autoridad en las casas de estudio. Los petitorios mutan y se convierten en verdaderos manifiestos que describen la educación como una herramienta que reproduce sistemas sociales, culturales, e ideológicos que perpetúan el patriarcado y el colonialismo. En muchas universidades, profesoras y administrativas se pliegan al movimiento, participando de asambleas y mesas de trabajo.

A mediados de mayo, la palabra feminismo no sólo resonaba en las escuelas y universidades, se podía escuchar en cada conversación. Los susurros de los pasillos y aulas universitarias se convirtieron en gritos desaforados en el espacio público. Como estableció el Observatorio de Política y Redes Sociales de la Universidad Central, durante mayo 2018 la búsqueda de Google más frecuente fue: “feminismo", con un peak en los días 15 al 17 de mayo previo a la marcha del 16 de mayo. El movimiento fue ganando una fuerte adhesión en la sociedad chilena. El 23 de mayo, según la encuesta CADEM, 71\% de los chilenos apoya las demandas del movimiento y $65 \%$ apoya las protestas y marchas feministas. Las consignas feministas empiezan también a resonar en los medios. Los titulares ya no sólo se concentran en los casos de abuso o acoso sexual para comenzar a describir un movimiento transversal que criticaba el patriarcado estructural, la violencia sexual y las abismantes diferencias de privilegios entre hombres y mujeres. Uno de los logros más importantes del movimiento fue justamente haber logrado tomarse la agenda, con críticas profundas y estructurales a la cultura heteronormativa y patriarcal en general.

El 23 de mayo el presidente Sebastián Piñera, ambicionando una pequeña dosis de la creciente popularidad del movimiento, da a conocer la agenda de género del gobierno. La propuesta evade con poca elegancia las demandas fundamentales del movimiento, proponiendo pequeñas reformas de corte más bien populista, como por ejemplo: "terminar con la discriminación que significa el impedimento a la mujer de contraer nupcias, antes de los 270 días desde la disolución del vínculo matrimonial, por divorcio, nulidad o muerte." Esta propuesta es un botón de muestra de la interpretación del movimiento por parte del gobierno del Presidente Piñera. Según ellos, una de las 12 preocupaciones más importantes de las mujeres en Chile es poder casarse lo antes posible después de un divorcio. La denominada agenda mujer del gobierno denota una clamorosa incomprensión de las reivindicaciones feministas, y a una férrea concepción heteronormativa y conservadora de la mujer que aparece vinculada al rol de madre o esposa. 
En las calles, las convocatorias a marchas reúnen a miles de personas que juntas exigen un cambio estructural de la cultura patriarcal en la que el país está sumido. Los medios hablan de la "ola feminista" retomando una de las metáforas predilectas con la que se describe los avatares de los feminismos. Según Rory Dicker la metáfora de la ola fue usada por primera vez en marzo de 1968 en un artículo del New York Times Magazine, firmado por Martha Lear, quien describió el surgimiento de una "segunda ola de feminismo" (5). La metáfora ha sido utilizada consistentemente para hablar de los feminismos ya que ha demostrado ser eficaz para capturar tanto las sucesivas avanzadas y resacas, así como las diversas corrientes y tendencias que se autoidentifican como feministas. La metáfora de las olas ha sido luego aplicada a contextos locales, como por ejemplo la revisión de la historia de los feminismos en Chile que propone Julieta Kirkwood (2010).

Me parece interesante constatar que el movimiento de mayo del 2018 en Chile refleja también las heterogeneidades de los feminismos. La primera marcha, por ejemplo, fue organizada por "Ni Una Menos Chile" en contra de la "cultura de la violación" y fue directamente motivada por dos casos que tuvieron amplia cobertura mediática: la violación de una mujer por cinco presuntos barristas de un equipo de fútbol y el caso de Ámbar, una niña de un año y siete meses que falleció a causa de la violencia sexual de la que fue víctima por parte de su tío político. No hay en estas consignas una pregunta sobre el género, el foco es la resistencia a la violencia contra la "mujer" concebida como una categoría autoevidente y biológicamente determinada. Esta concepción se acerca a los feminismos de la primera ola en el sentido que busca la reivindicación de los derechos de la mujer, entendida como una entidad identificable a partir del sexo biológico. El discurso de esta tendencia del movimiento feminista en Chile establece que la lucha se da entre mujeres y hombres. Muchas de las tomas adscriben a esta forma de feminismo y se constituyen como tomas separatistas, admitiendo el ingreso sólo a cismujeres.

A medida que pasan los días, van apareciendo otros matices, se van sumando, por ejemplo, las disidencias sexuales, las asociaciones de migrantes, incluso los sindicatos. Esto no es sólo un crecimiento cuantitativo del movimiento, se trata de otra forma de pensar y poner en acción el feminismo. Esta tendencia es más interseccional, en el sentido de denunciar simultáneamente distintos tipos de abuso, lo que permite apuntar los dardos contra la violencia y desigualdad estructural. ${ }^{1} \mathrm{El}$ tsunami feminista pone en operación lo que Judith Butler define en Cuerpos aliados

1 La principal exponente del feminismo interseccional es Crenshaw, Kimberle quien en 1989 publica el canónico artículo "Demarginalizing the Intersection of Race and Sex: A Black Feminist Critique of Antidiscrimination Doctrine, Feminist Theory and Antiracist Politics," donde desarrolla una crítica feminista que considera la intersección de las identidades marginalizadas, tomando en cuenta, por ejemplo, 
y lucha política (2017), como una alianza y una ética de la cohabitación que reconoce que los derechos hay que disputarlos en el horizonte de la justicia social, es decir que no se pueden obtener derechos en desmedro de los derechos de otros individuos, grupos o comunidades en situación de vulnerabilidad (72). Esta corriente dentro del movimiento entiende que las mujeres no son las únicas precarizadas, de hecho, el 6 junio más de 100.000 en Santiago se congregan bajo el lema de carácter interseccional: "Precarización vivimos todas: a la calle estudiantes, migrantes, madres y trabajadoras".

Otro ejemplo de interseccionalidad y de ética de la cohabitación se da en el contexto de la toma de la Casa Central de la Universidad Católica (UC), donde uno de los puntos del petitorio titulado "Subcontrato" exigía la contratación de los y las trabajadoras subcontratadas en la UC. El petitorio se concentraba en la situación de trabajadorxs extranjerxs subcontratadxs, demandando el pago de las horas extras acumuladas que no habían sido remuneradas, la desvinculación de la empresa que externalizaba los servicios y sanciones para quienes estuvieran en conocimiento de la vulneración de derechos de lxs trabajadorxs subcontratadxs. Este punto fue una de las peticiones en las que se logró acuerdo con las autoridades universitarias, lo que se tradujo en mejoras concretas en las condiciones laborales de las personas afectadas.

Otro ejemplo de la ética de la cohabitación es la ocupación del Instituto $\mathrm{Na}$ cional por parte de las estudiantes secundarias del Liceo Carmela Carvajal, uno de los liceos exclusivos para varones más emblemáticos del país. La acción se realiza, según explican las mismas estudiantes, en solidaridad con una mujer migrante trabajadora del Instituto que denunció a un estudiante por acoso sexual. La ética de la cohabitación surge con fuerza en forma transversal en el movimiento que aprendió a generar alianzas desde el reconocimiento de la precariedad propia y ajena.

En paralelo, aparece una tendencia que podríamos vincular más con el feminismo queer ${ }^{2}$ que rechaza concepciones biologicistas y ontológicas de los géneros y que abogan por el derecho a la performatividad del género. Algunos petitorios incluyen, por ejemplo, el reconocimiento institucional del nombre social.

la diferencia en términos de privilegios de las mujeres blancas heterosexuales respecto a mujeres negras o de disidencias sexuales.

2 Se considera como una de las precursoras del feminismo queer a Teresa de Lauretis, quien, en su publicación “Tecnologías de Género", explica que el sexo es una interpretación arbitraria de los marcadores biológicos. Más tarde, el feminismo queer se consolida a partir de la teoría de la performatividad de género expuesta en "Gender Trouble" (1990) donde Judith Butler argumenta que el género es socialmente construido y está siempre performado y socialmente construido. 
Más allá de las heterogeneidades, las feministas de la rebelión de mayo 2018, no se contentan con identificarse con la metáfora de la ola. En la marcha del 6 de junio, una de las voceras declara: "Fuimos ola y nos convertimos en tsunami". La metáfora nunca había sido tan afortunada. Era difícil concebir la gran cantidad de movilizaciones como una ola singular, parecía mucho más adecuado pensar el movimiento en términos de un tsunami. Mayo del 2018 quedará en la memoria colectiva del país como el mayo feminista, donde se alzaron las voces y los cuerpos de personas y comunidades en resistencia al sistema heteropatriarcal.

\section{Feminismos en Chile: avanzadas y resacas}

Los movimientos sociales nunca tienen un inicio certero, se van gestando de a poco, confluyen en estos motivaciones históricas y coyunturales que colaboran en formas complejas para producir los estallidos de movilizaciones. El caso del movimiento feminista en Chile no es la excepción. Podemos pesquisar antecedentes de larga y corta data, identificar factores contextuales e intentar comprender por qué mayo del 2018 fue el momento en el que miles de personas en Chile se congregaron bajo la bandera del feminismo. Sin pretensión alguna de exhaustividad, en lo que sigue reviso algunos hitos y procesos que, me parece, catalizaron el tsunami feminista de 2018 en Chile.

Desde el punto de vista histórico, el mayo feminista en Chile surge desde una serie de gestos, acciones y movimientos anteriores. Tal como plantea Faride Zerán:

. . si leemos la epidermis de este movimiento podemos ver que más allá de su heterogeneidad existe un continuo mediante el cual las históricas reivindicaciones de mayor democracia, libertad e igualdad, dialogan no sólo con parte de los feminismos actuales sino con una tradición de lucha de las precursoras feministas de siglos anteriores (10).

$\mathrm{El}$ activismo de mujeres en Chile tiene una historia que, por cuanto heterogénea y variable, es contundente y poderosa. Las primeras movilizaciones en 1913 se concentran en la lucha por la obtención de derechos civiles y políticos para las mujeres. Este movimiento, coincide con el movimiento internacional sufragista que se manifestó en varios países para la obtención del derecho a voto. A principios del siglo XX se conforman los Centros Femeninos Belén de Zárraga (vinculado a la clase obrera), el Club Social de Señoras (cuyos miembros eran mujeres de la aristocracia) y los Círculos de Lectura donde participaban mayoritariamente mujeres laicas de clase media. En 1922 se crea el Partido Cívico Femenino y en 1935 el Movimiento Pro Emancipación de la Mujer Chilena (MEMCH), emblemática 
organización liderada por Elena Caffarena que luchó por la igualdad política y jurídica de la mujer. En 1949, durante el gobierno de Gabriel González Videla, se logra el derecho a voto para las mujeres. En la década del cincuenta se produce lo que Julieta Kirkwood denomina "mutismo feminista", un repliegue del feminismo que se explica por la integración de las mujeres en los partidos políticos y la pérdida de protagonismo de las cuestiones de género. El silenciamiento dura hasta los setenta.

En el contexto de la dictadura, las asociaciones feministas y de mujeres trabajan desde la clandestinidad para sumar sus fuerzas a otras organizaciones que luchaban por la recuperación de la democracia. El activismo feminista se articula con otras organizaciones para resistir ante el autoritarismo y el patriarcado. Entre 1977 y 1981 funciona el Círculo de Estudios de la Mujer y las agrupaciones de mujeres empiezan a vincularse en forma más decidida con el feminismo latinoamericano, asistiendo, por ejemplo, al Encuentro Nacional de las Mujeres, y al Primer Encuentro Feminista de Latinoamérica y el Caribe. Los últimos años de la dictadura, proliferan las coordinadoras de grupos de mujeres y se empiezan a plantear objetivos políticos para la vuelta a la democracia.

La posdictadura lejos de consolidar la rebelión feminista, genera una serie de quiebres y rupturas. La creación en 1991 del Servicio Nacional de la Mujer produce la consabida rencilla entre las feministas autonomistas (que rechazan la integración a la oficialidad) y las institucionalizadas (que deciden trabajar desde las nuevas estructuras democráticas). Según Schild, en los 90 se produce un ulterior debilitamiento del feminismo, lo que podría explicarse por el embate del neoliberalismo que construye una estructura de financiamiento y apoyo al que sólo pueden acceder las feministas letradas capaces de redactar proyectos y medir sus impactos de acuerdo a lógicas imperantes (45).

El espesor del actual movimiento feminista se va construyendo también en los bordes del movimiento estudiantil que, desde el 2006, configura una crítica a la mercantilización de la educación. Luna Follegati delinea el trayecto de articulación del feminismo en el contexto de las demandas del movimiento estudiantil. Según la autora, hasta el 2011 el movimiento estudiantil posee "rasgos característicos de una política masculinizante" (278), pero en este período inicia un cuestionamiento más sistemático de la inclusión y diversidad en los espacios universitarios. Como un hito relevante, en estos años se crean las Secretarías de Sexualidades y Género, orgánicas cruciales para la articulación de una política feminista al interior de las universidades: 
Colectivos y organizaciones comienzan a reaccionar, a despertar frente a un quietismo que había omitido sistemáticamente el trato despectivo, la estigmatización y vulneración derivadas de la diferencia genérica y sexual. Para el año 2012, las Secretarías de Sexualidades y Géneros comienzan a existir en las distintas universidades, buscando de manera intuitiva información, protocolos y acciones que pudiesen guiar su accionar (Follegati 279).

Con el objetivo transversal de revertir las prácticas machistas y patriarcales tan arraigadas en la universidad, las Secretarías de Sexualidades y Género organizan diversas actividades como foros, seminarios y conversatorios. Resulta paradójico que mientras se producía esta progresiva politización feminista, la clase política se encuentra completamente desfasada. Un ejemplo radical es la penosa recriminación que justo por esos años, el año 2012, hace el entonces alcalde de Ñuñoa Pedro Sabat a las estudiantes secundarias movilizadas tildándolas de "putas".

El 2014 se organiza el "Primer Congreso Nacional por una Educación no Sexista”, encuentro que tal como describe Follegati, congregó la participación de diversas Secretarías y Vocalías de Sexualidades y Géneros erigiéndose como un hito programático del movimiento (281). El movimiento feminista crea sus propios espacios y se autonomiza del organigrama político de las federaciones de estudiantes, alegando la poca importancia que se le otorgan a sus demandas en las federaciones centrales. Así es como el 2016 La Coordinadora Feminista Universitaria (COFEU), que luego tendrá un rol crucial en el tsunami feminista, se independiza respecto a la Confech.

Ese mismo año, Nabila Riffo sufre una terrible agresión por parte de su expareja, quien fuera hallado culpable de homicidio frustrado. En octubre de 2016 las organizaciones de mujeres y feministas convocan a una marcha masiva bajo el lema \#Niunamenos como apoyo a Nabila y a las decenas de otras víctimas de femicidios. Algunos meses después, el 8 de marzo de 2017, se realiza una marcha por el Día de la Mujer en la que se denuncia los femicidios que, sólo en los primeros dos meses del año en curso, habían cobrado la vida a once mujeres.

En el paisaje internacional, el 2018 los movimientos \#Me'Too y \#NiUnaMenos instalan el problema del abuso y acoso sexual en la agenda mundial. En Chile, se produce una versión criolla del \#Me'Too a raíz de reportajes que publican denuncias de abuso sexual contra el director de televisión Herbal Abreu, generando gran revuelo en la prensa. A este primer caso seguirán una seguidilla de denuncias contra hombres del mundo del cine, la televisión y la cultura. 
Pero el caldo de cultivo del movimiento feminista excede estos (lamentablemente múltiples) casos de violencia sexual. Como plantea Diamela Eltit:

Pienso que una forma de cataclismo institucional detonó una "tormenta perfecta": los Carabineros y el Ejército con sus saqueos a los fondos públicos, los partidos y las crisis de los políticos de Soquimich, la derecha Penta, el cohecho de las pesqueras. Y, de manera estruendosa, la Iglesia chilena. Todos colapsaron en tiempos si no sincrónicos, al menos similares, ocasionando un nítido malestar en parte de la ciudadanía que confiaba, se comprometía y hasta admiraba algunos de estos frentes (59).

Me parece imprescindible considerar todos estos antecedentes temporales, algunos más lejanos y otros más coyunturales, para comprender de mejor forma los mecanismos y tácticas que puso en funcionamiento el movimiento feminista del 2018. Como mencioné en la introducción, me ocuparé en este escrito principalmente de las prácticas del movimiento feminista, de las formas cómo los feminismos se escenificaron en el espacio público y cómo organizaron sus prácticas. Los antecedentes al movimiento no son sólo antecedentes históricos, forman también sedimentos discursivos y corporizados que se expresan en el movimiento actual. Los gestos, las prácticas, las acciones de las feministas chilenas que precedieron forman palimpsestos que los cuerpos de las actuales protagonistas replican, reproducen y reproponen.

\section{La toma como performativo político}

En este apartado quisiera pensar el rol de las tomas en el movimiento feminista, en particular, quiero reflexionar sobre las prácticas de organización de las tomas y su eficacia para la articulación del movimiento. Una toma es, por definición, la ocupación ilegal de un espacio como protesta política: implica instalarse en un lugar, habitarlo, secuestrarlo, en pocas palabras, dejar de moverse para quedarse. Quedarse para evitar que otros entren. La forma de operatividad de la toma es, en ese sentido, opuesta al significado semántico de una "movilización”, que expresa, en cambio, que algo se mueve. En la toma no hay tránsitos o desplazamientos. La toma es quieta. Pero la toma es acción que tiene un objetivo y genera una transformación. La toma nunca es inocua, la toma es insurrecta, rebelde, insumisa.

La eficacia política del gesto refractario de las estudiantes del mayo feminista en Chile tiene múltiples niveles de eficacia política. Por un lado, el gesto insurrecto rompe el status quo, fracturando la institucionalidad y quebrando las formas de diálogo y negociación. Es, en ese sentido, un rechazo a las formas políticas de 
comunicación y la propuesta de un nuevo orden. Sin querer justificar las tomas, que tienen también una valencia violenta, es interesante pensar la toma en términos performativos. A pesar de tener un carácter reactivo que busca la transformación de algo que pre-existe, la toma es también un atisbo de un mundo posible que se actúa y se comprende mientras ocurre la ocupación. Tal y como propone Nelly Richard, las insurgencias feministas pueden entenderse como un performativo político (119). En este punto, me gustaría profundizar la tesis de Richard para explicar el carácter de performativo político de la toma. Según Benjamín Arditi, los performativos políticos son "acciones y declaraciones que anticipan algo por venir a medida en que los participantes empiezan a experimentar-conforme comienzan a vivir-aquello por lo que luchan mientras luchan por ello." (5-6). Las tomas generan las condiciones de posibilidad para una comunidad, en la toma se vive de otra forma, y a la vez se prueba performáticamente que otra forma de vivir es posible.

Desde este punto de vista, las tomas feministas reivindican los principios del movimiento mientras ponen a prueba la factibilidad de una comunidad feminista. Algunos de los principios del mundo posible feminista experimentados fueron la democracia directa y la justa distribución de los derechos y deberes comunitarios. En las tomas, esto se traducía en que su inicio y término eran determinados en asambleas con voto directo. A diferencia de lo que sucedía en el contexto del movimiento estudiantil, en el movimiento feminista las negociaciones con las autoridades para deponer las tomas volvían irremediablemente para ser sancionadas por la asamblea. Los trabajos en las tomas se organizaban en forma distribuida y rotativa -guardias, voceras, responsables de intercambio de alimentos con el exterior- se iban turnando e intercambiando. Esto evitaría, según las participantes, una verticalización del movimiento. Una diferencia notable con el movimiento estudiantil, que se desprende de estas formas de organización, es la falta de "rostros" de liderazgo del movimiento.

El mundo posible feminista de la toma pone también en acción procedimientos de solidaridad y mecanismos de autocuidado. Distintas versiones del feminismo comprenden la solidaridad de diferentes maneras, pero podría decir que en todos hay una búsqueda de la comprensión y empatía de la vulnerabilidad ajena. La solidaridad feminista requiere una política de los afectos que abrace sensorialidades, corporalidades y afectos como parte integrante del ser feminista. Siguiendo estos principios es que muchas tomas establecieron horarios de actividades colaborativas como talleres de autodefensa, bordado de resistencia, stand-up feminista o lecciones ginecológicas. Asimismo, programaban actividades de autocuidado como escuchas mutuas. La atención al cuidado mutuo responde a los principios de sororidad y solidaridad que los feminismos promueven. 
Otro aspecto de la performatividad de la toma es que, como explica Judith Butler, las tomas aseguran las condiciones materiales para poder aparecer en público. Según la autora, si el espacio para aparecer políticamente estuviera garantizado, probablemente las tomas no ocurrirían: "Esta clase de acciones no suelen llevarse a cabo cuando se dispone de plataformas efectivas" (98). Atrincherarse en un espacio es disputar la posibilidad de adueñarse o de recuperar un espacio que se siente ajeno, pero que se piensa debería ser propio: "de este espacio hemos sido excluidas y ahora lo estamos reclamando". Como bien escribe Alejandra Castillo: "Esta revuelta no sólo ha tomado lugar, sino que se ha tomado el lugar" (35). Las estudiantes feministas querían tomarse la palabra, pero para hablar era necesario tener un espacio desde donde proferir sus voces. Asimismo, querían aparecer políticamente, no determinadas por la mirada de los otros, sino que autodeterminadas por sus propios principios y deseos. Ante décadas, sino siglos, de patriarcado, para aparecer políticamente no bastaba "salir a la calle", era imprescindible construir un lugar simbólico del habla y de la enunciación encarnada de los cuerpos.

La toma, en este contexto, es aquello que permite catalizar la comunidad y propulsar la acción política. La toma se configura como un espacio liminoide, que según Victor Turner es una protoestructura que se sitúa al margen de la estructura desde la que emergen nuevas formas sociales (169). Lo liminoide se construye como un horizonte donde opera la transición de un estado a otro (173), donde se rechaza y trasciende la fijación y las reglas de la estructura. Tal como el rito de pasaje de las sociedades simples, en las sociedades contemporáneas aquello que se pone a prueba en los sistemas liminoides se recrea en la reinserción en lo social. Las tomas funcionan justamente como este espacio protoestructural que avizora una nueva estructura, la pone en acción para luego recrearla.

La toma se emparenta así con el ritual, donde las reglas sociales se suspenden para probar un nuevo orden. La toma como ritual, tiene una gran eficacia simbólica: genera comunidad, sincroniza afectos, organiza corporalidades. La infraestructura, como ambiente material de este ritual, no "contiene" la acción, sino que se refuncionaliza en la acción. Como una nueva capa de significado incrustado en las materialidades, las facultades y campus tomados guardan una nueva pátina que reconfigura su significado. Desde este punto de vista, el acto de tomarse un espacio es en el fondo refundar el significado que dicho espacio detenta.

Siguiendo las hipótesis de Butler, que insiste en la factibilidad material de resistencia política (76), cabe preguntarse cómo la falta de este espacio reconfigurado por la toma afecta el debilitamiento del movimiento e incluso el riesgo de su extinción. Aún con los triunfos políticos obtenidos, la deposición de la toma 
dejó en sus precursoras un amargo sabor a utopía perdida. El rito ha terminado. El movimiento tiene el desafío de poder sostener una comunidad que no dependa de la intensidad de los afectos que se ponen en circulación en el momento pivotal de la toma. En la misma línea, resta el desafío de construir una comunidad que no sea reaccionaria y que pueda, de una forma u otra, perseverar en un proyecto de construcción del anhelado modo de vida feminista. Resta, en definitiva, el desafío de mutar la resistencia a otras formas más sostenidas de acción colectiva.

\section{La puesta en cuerpo como reversa de la vulnerabilidad}

Si los procedimientos feministas de las tomas lograron generar una comunidad e instalar un lugar de legitimidad para hablar, las marchas y manifestaciones fueron los contextos donde estas colectividades pudieron desplegarse expresivamente. Los dispositivos puestos en cuerpo en las marchas y manifestaciones no pueden entenderse sin la experiencia de comunidad construida en las tomas y los paros; al mismo tiempo, las marchas sirven para generar una cadencia que da ritmo a la toma que, de lo contrario, quedaría sumida en un espacio liminoide indefinido.

Las manifestaciones colectivas muchas veces se definen como formas de ocupar un espacio público. La teoría de la asamblea de Butler, sin embargo, llama la atención sobre la falacia de pensar las movilizaciones en estos términos. "Ocupar" el espacio público, sería dar por sentado que el espacio público pre-existe la movilización, cuando como bien hace ver Butler, la multitud de cuerpos, al salir a la calle, disputa lo público al mismo tiempo que lo produce:

Los cuerpos en su pluralidad reclaman lo público, encuentran y producen lo que es público a través del apropiamiento y la reconfiguración de los entornos materiales; y estos, a su vez, son parte de la acción, pero al mismo tiempo actúan cuando se convierten en el soporte de la acción (76).

Un interesante ejemplo de la disputa de lo público se produjo en la marcha del 16 de mayo cuando un ejército de mujeres encapuchadas y con el torso desnudo marcharon vigorosas por las calles de la ciudad. El contingente de encapuchadas, casi todas estudiantes de la Pontificia Universidad Católica, ostentó sus pechos mientras ocultaban sus rostros. Con una vibrante fuerza colectiva se encumbraron en las vallas papales dispuestas frente al Palacio de La Moneda, desplegaron vigorosas coreografías en su trayecto mientras vociferaban "Y cómo, y cómo, y cómo es la hueá, nos matan y nos violan y nadie hace na".

Uno de los gestos que generó más polémica, fue cuando varias estudiantes treparon las estatuas que representan autoridades eclesiásticas y de la misma universidad. 
El gesto produjo una de las imágenes más emblemáticas del movimiento: encapuchadas con sus pechos descubiertos sobre los símbolos de la autoridad patriarcal. El gesto insurreccional fue percibido como una insolencia y profanación de los emblemas universitarios y eclesiásticos. Sin justificar el hecho, que fue percibido como violento y ofensivo, desde el punto de vista del análisis de la performance política es interesante pensar cómo el gesto reconfigura la materialidad de ese espacio. Estas estatuas nunca más serán "las mismas", la memoria colectiva de la universidad e incluso del país, no podrá sino recordar la imagen, casi épica, de jóvenes mujeres encapuchadas sobre estas, manifestando su furia contra lo que las estatuas representan. En el gesto no hay discurso, no hay palabra más que aquella escrita en unos panfletos fotocopiados pegados precariamente en la figura que denuncian: "La UC encubre el abuso", "Aquí se titulan violadores". La dinámica refleja las formas de comunicación política de estos tiempos, que se basan, sobre todo en la población más joven, en la puesta en circulación de imágenes más que de discursos. Esto es algo que la performance entendió muy bien: la escenificación, la esteticidad, la protesta y la política funcionan sinérgicamente y son más elocuentes cuando se construyen amalgamadas.

En esta acción colectiva, los cuerpos femeninos disputan el espacio público y se rebelan ante las condiciones de existencia que el patriarcado produce y perpetúa. Como rezaban memes que circulaban por las redes sociales, las calles son espacios que detentan peligro para las mujeres y las disidencias sexuales. Las tradicionales recomendaciones de "no andar solas" tienen su justificación en la altísima tasa de agresiones a mujeres y minorías en el espacio público. Pues bien, este contingente de encapuchadas ejecuta un reverso performativo como si estuvieran declarando "vamos a ir juntas pero a protestar, a disputar nuestro espacio y a tomarnos nuestro derecho a aparecer como queremos". La acción es a la vez física -salen a las calles y hacen uso de estas de la forma como ellas disponen-, y representacional en el sentido de poner en escena la revancha ante el mandato patriarcal que determina qué comportamientos y vestimentas les están "permitidas". Para estas jóvenes los cuerpos devienen el sustrato y objeto de la insurrección y rebelión política.

Es justamente el uso del cuerpo como sustento y declaración política que produce la reversa de la posición de vulnerabilidad a la que están sometidas las vidas precarizadas (como las llama Butler). Las encapuchadas a torso desnudo muestran en un complejo clivaje la precariedad y su derecho a existir. El escuadrón ostenta una vigorosidad corporal y política en sus coreografías, cantos y acciones. Lo que ocurre en esa colectividad de cuerpos femeninos es una puesta en circulación de afectos de alta intensidad, que, podemos suponer, mezclan la rabia, la excitación, la esperanza. Los cuerpos sintonizan en la alta frecuencia de agitación, se 
empoderan y potencian mutuamente. Lo que acontece allí no es una suma de cuerpos, es un sistema intercorporal que encuentra su fuerza y vigorosidad en la acción que ejecuta. Y este sistema colectivo intercorporal se convierte, en sí mismo, en una potente declaración política.

Me parece interesante pensar esta performance como la revisitación de repertorios de protesta. Para Diana Taylor, el repertorio es la memoria encarnada: las performances, las prácticas, las acciones efímeras realizadas en co-presencia que conservan y transforman las coreografías colectivas de sentido. Más allá de las demandas específicas y locales de los movimientos sociales, es innegable que hay prácticas y acciones que se repiten, se citan, se reciclan. Diana Taylor los describe como memes, gestos y acciones que se replican y cuya fuerza política radica en su capacidad de repetición, contagio y su habilidad para "pegar" en contextos disímiles (115). Los zapatos para significar la ausencia de las víctimas, los sit-in o die-in's que han sido ocupados para los más diversos fines políticos, las huelgas de hambre, entre muchos otros. Si para dispositivos textuales se habla de intertextualidad, propongo que en ámbito del activismo pensemos en términos de una interrepertoriedad, es decir, en los procedimientos mediante los cuales las prácticas y acciones se replican y reciclan, citándose mutuamente. La puesta en circulación de los repertorios de protesta es independiente a la conciencia o el conocimiento explícito de sus participantes respecto a las interacciones anteriores, es más bien un fenómeno de contagio cultural diacrónico que no necesariamente pasa por las voluntades.

La acción de las encapuchadas del mayo feminista en Chile puede entenderse justamente como una interrepertoriedad de otros comportamientos y otras acciones de protesta. El gesto se inscribe en la genealogía del uso de la desnudez como protesta que ha sido utilizado por muchas artistas y activistas del feminismo. Los torsos desnudos, signos de rebeldía y resistencia, desplazan las connotaciones sexualizadas y maternales que se asocian persistentemente al cuerpo femenino. La desnudez corporaliza la fisura entre lo que la heteronorma patriarcal permite y prohíbe a los cuerpos. La acción colectiva reconquista así la propiedad sobre el propio cuerpo y el derecho a decidir cómo portarlo y vivirlo. El batallón de encapuchadas acciona desde otro lugar de subjetividad, un lugar corporal donde la carne no debe ni esconderse ni disponerse ante la mirada patriarcal, sino que puede desplegarse desde la propia libertad. La ostentación del propio cuerpo subvierte la frontera entre lo privado y lo público. Actúa, en versión recargada, el lema "lo personal es político".

Otro fenómeno de interrepertoriedad es el uso de los pasamontañas, que también se inscribe en un linaje de acciones de protesta, desde el colectivo feminista 
ruso Pussy Riot, pasando por la película V de Vendetta, o los zapatistas; muchas organizaciones subversivas y artísticas han utilizado este recurso. Las máscaras se usan por razones prácticas, para ocultar la identidad evitando las consecuencias de la propia acción, pero tiene también toda la densidad simbólica de sus usos anteriores. En el caso de las estudiantes de la Universidad Católica, el gesto sirve por un lado para evitar su identificación y las posibles represalias por parte de las autoridades y a la vez sirve como cita corporizada a otros movimientos sociales en el mundo y la historia.

La interrepertoriedad no es sólo repetición, también propone nuevos usos de las prácticas corporales que replica. En este caso, resulta clave el hecho de que los pasamontañas de las manifestantes feministas estaban cuidadosamente personalizados con aplicaciones y bordados. En este caso, el pasamontaña no borra la individualidad, no hay aquí uniformes, muy por el contrario, la individualidad se ostenta sobre la capucha. La individualidad aparece cifrada ante la mirada pública, pero se dice y se manifiesta en esos zurcidos y bordados. El gesto es bello porque además se vincula, como interrepertorio, con las labores de cosido y bordado típicamente realizadas por las mujeres en la privacidad de lo doméstico. La acción de coser adquiere otro valor, ya no es la acción sumisa que se realiza en el propio hogar, deviene una acción que se proyecta a la calle, a la protesta, a la marcha. Las subjetividades restan ahí en las piedrecillas bordadas que conservan las huellas de la gestualidad que las produjo, evidenciando una temporalidad otra respecto a la temporalidad de la marcha. El tiempo de la protesta es rápido, veloz, contingente. Pero los pasamontañas bordados indican el tiempo lento y pausado de la preparación de la acción colectiva. El bordado requiere un tiempo de calma, el tiempo de los oficios manuales, el tiempo de la solidaridad y la resistencia. El pasamontaña bordado concentra así un rizoma de connotaciones: lo subversivo y lo tradicional, el anonimato y la individualidad, el tiempo de la lucha y el tiempo doméstico de los oficios. El gesto deviene feminista en toda su expresión, colapsando binarismos para proponer nuevas formas de pensar y de hacer lo femenino.

\section{E1 futuro esplendor}

El tsunami feminista sin duda logró desplazar los límites de lo concebible al tiempo que modificó las narrativas a través de las cuales entendemos el mundo en el que vivimos. El movimiento instaló una discusión sobre la violencia sexual, el rol de la mujer y las disidencias sexuales, la educación sexista y también sobre la distribución de los privilegios en nuestra sociedad. Como nunca antes se desmanteló la naturalización de la violencia de género, entendida no sólo desde el acoso y el abuso sexual, sino también desde la norma de género que exige adscribir a una 
identidad heterosexual que distribuye en forma injusta el poder, generando efectos de exclusión de quienes escapan de esta lógica binaria. Provocó, además, un efecto doble y transversal que permitió identificaciones tanto con el lugar de la vulnerabilidad de las personas precarizadas, como con la fuerza y poderío que ostentaba el movimiento.

El tsunami feminista ocupó tácticas corporales que lograron una eficacia transformadora, obteniendo triunfos no despreciables en la arena política universitaria e incluso nacional como, por ejemplo, la aprobación de la ley de identidad de género algunas semanas después del despertar feminista. Resta el futuro, como siempre abierto e indeterminado, para descubrir las nuevas formas de puesta en cuerpo y en acción que el activismo feminista pondrá en marcha en los próximos tiempos. 


\section{Obras citadas}

"Más de 30 universidades ya están movilizadas por demandas feministas". Cooperativa.cl. 29 de mayo 2018. Visitada 30 septiembre 2018. https:// www.cooperativa.cl/noticias/pais/educacion/movimiento-estudiantil/ mas-de-30-universidades-ya-estan-movilizadas-por-demandasfeministas/2018-05-29/123325.html

Araditi, Benjamín. "Las Insurgencias No Tienen un Plan - Ellas Son el Plan: Performativos Políticos y Mediadores Evanescentes". Revista Sul-Americana de Ciência Politica 2, 8 (2013): 1-18.

Butler, Judith. Cuerpos aliados y lucha política. Buenos Aires: Paidós, 2017.

Butler, Judith. Gender Trouble. Feminism and Subversion of Identity. Londres: Routledge, 1990.

CADEM. "ENCUESTA N²27 - 22 DE MAYO”. 22 de mayo 2018. Web. Visitada el 1 de junio 2018. https://www.cadem.cl/encuestas/encuesta-n227-22-demayo/

Castillo, Alejandra. "De la revuelta feminista, la historia y Julieta Kirkwood". Mayo feminista. La rebelión contra el patriarcado. Ed. Faride Zerán. Santiago: LOM. 2018: $35-48$.

Crenshaw, Kimberle. "Demarginalizing the Intersection of Race and Sex: A Black Feminist Critique of Antidiscrimination Doctrine, Feminist Theory and Antiracist Politics". University of Chicago Legal Forum. Vol. 1989 (1998). Visitado 30 diciembre 2018. http:// chicagounbound.uchicago.edu/uclf/vol1989/iss1/8

De Laurentis, Teresa. "La tecnología del género". Mora, Revista del Área Interdisciplinar de Estudios de la Mujer 2 (1996): 8.

Dicker, Rory. A history of U.S. feminisms. Berkley: Seal Press. 2016.

Eltit, Diamela. "No hay plazo que no se cumpla". Mayo feminista. La rebelión contra el patriarcado. Ed. Faride Zerán. Santiago: LOM. 2018: 59-65.

Follegati, Luna. "El feminismo se ha vuelto una necesidad: movimiento estudiantil y organización feminista (2000-2017). Revista Anales. Séptima Serie 14. (2018): 261-291.

Kirkwood, Julieta. Ser politica en Chile. Las feministas y los partidos, LOM Ediciones y Facultad de Ciencias Sociales, Universidad de Chile, 2010. 
Molina, Tomás y Ferrer, Consuelo. "Fuimos ola y nos convertimos en tsunami": Multitudinaria marcha feminista recorrió la Alameda de manera pacífica". Emol. Enero 6 junio 2018. Web. Visitada 3 enero 2018. https://www.emol. com/noticias/Nacional/2018/06/06/908894/Fuimos-ola-y-nos-convertimosen-tsunami-Multitudinaria-marcha-feminista-recorrio-la-Alameda-de-manerapacifica.html

Observatorio políticas y redes sociales. "Ola feminista se toma las redes sociales". Observatorio política y redes sociales. 23 de mayo 2018. Web. Visitada el 1 de octubre 2018. https://www.politicavredessociales.cl/single-post/2018/05/23/ Nuevo-estudio-Ola-Feminista-se-toma-las-Redes-Sociales

Richard, Nelly. "La insurgencia feminista del mayo 2018". Mayo feminista. La rebelión contra el patriarcado. Ed. Faride Zerán. Santiago: LOM, 2018: 115-125.

Taylor, Diana. "Traumatic memes". Women Mobiliz̨ing Memory. Ed. Ayse Altýnay, María José Contreras, Marianne Hirsch, Jean Howard, Banu Karaca and Alisa Solomon. Nueva York: Columbia University Press, 2019.

"Toma feminista en el Instituto Nacional: alumnas del liceo Carmela Carvajal protestan contra el establecimiento". CNN Chile. 15 mayo 2018. Web. 16 mayo 2018. https://www.cnnchile.com/pais/toma-feminista-en-el-instituto-nacionalalumnas-del-liceo-carmela-carvajal 20180515/

Turner, Victor. Antropología del ritual. México: Edit. Romero Hernández. 2002.

Schild, Verónica. "Feminismo y neoliberalismo en América Latina". Nueva Sociedad 265. (2016): 32-49.

Zerán, Faride. "Prólogo. Escrituras rebeldes para tiempos de cambios". Mayo feminista. La rebelión contra el patriarcado. Ed. Faride Zerán. Santiago: LOM, 2018. $9-20$. 